\title{
Motivational Factors and Organisational Commitment of the Educational Institution's Employee
}

\author{
Msc. Julinda Sinani \\ Place of work: Msc.Part-time Lecture at the University of Tirana \\ Email: sinanijulinda03@gmail.com
}

\section{Doi:10.5901/jesr.2016.v6n1p89}

\begin{abstract}
Motivation and organizational commitment of employees is an important element to enhance job performance. A significant predictor of this commitment is also the type of motivation, which motivates teachers to spend time and energy at work. Due to this fact there is a growing interest to understand the relationship between motivation and commitment. Despite many researches on motivation and organizational commitment, the relations between different forms of motivation and organizational commitment in Albania have been studied very little. The main reason for the realization of this research is the lack of sufficient research to study the relationship between these two variables in our country and the impact they have on human resources within organizations / institutions in Albania. In this research is used the quantitave scientific research method. For data collection were used two questionnaires "Work Motivation Questionnaire" and the "Organizational Commitment Questionnaire". The study revealed that motivational factors influence the organizational commitment of teachers at work.
\end{abstract}

Keywords: organizational commitment, work motivation, teachers

\section{Introduction}

Educational institutions are the main premises in which the new generation is educated and the subject that supports them in this journey is the whole teaching staff. Their motivation in the work environment has a direct impact on the commitment at work, on the institution in general and in particular on the learning process. Technological development in our society is changing rapidly and it is really necessary for teachers and employees to be motivated as much as possible to engage in these developments that will cultivate their teaching process.

The motivating factors' impact on the employees' organizational commitment has a great importance, therefore their good functioning should be one of the primary issues of the educational institutions' employees. Thus, we can say that motivation is the factor that encourages employees to improve their performance and enhance productivity (Tung, 1981). Different researchers provide different perspectives on the importance that employees' work commitment has in their performance at work. Motivation functions as an important predictor of employees' commitment to spend time and energy in the organisation in which they are employed ( Mowday, Steers \& Porter, 1979). Due to this fact there is a growing interest in understanding the relationship between motivation and organizational commitment.

The aim of the article: This study aims to identify the relationship that exists between the motivating factors at work and the organizational commitment of teachers in education institutions, in the region of Tirana and Elbasan.

The objectives of the study:

1. To research on the relationship that exists between the motivating factors and the organisational commitment of the education institution's employees, in the region of Tirana.

2. To research on the relationship between the organisational commitment and demographic data (age, rural/urban area)

This study is designed to be realized based on two research questions, as follows:

- Does organisational commitment at work depend on the independant variables: Salary and Benefits, Work conditions, Relations with colleagues, Relations with directors, Tasks' Orientation, Cooperation with colleagues, orientation toward the goal and orientation toward success. Which of them affect most?

- Are there differences in the commitment of teachers at work because of the fact that the teacher works in urban or rural area? 


\section{Motivation and Its Importance at Work}

Motivation at work is related to a set of factors that determine the behaviour within the organisation, its shape, orientation, intensity and duration. It is often used as a tool to predict the individuals' behaviour in the work place and it varies a lot among individuals. Also its combination with the capabilities of environmental factors affects work behaviour and performance of employees in every institution/organisation. Understanding what motivates the employees is the focus of many studies in the field of organisational psychology. Various scholars have given different ideas about employees' motivation at work. According to Mitchel and Daniels motivation includes "behaviour patterns produced to reach a specific goal". Another scholar considers it as a promoter of people's activities and behaviours on the will for achievements on education and teaching terms (Analoui, 2000). Motivation at work and in various contexts is of an internal and external affecting nature (Sansone \& Harackiewicz 2000). Motivational factors have a significant impact on the work performance of educational institutions' employees. Being motivated influences for a positive performance, which enhances the academic level of education.

Pinder ( 1998) gives another interesting definition on motivation: Motivation at work is a group of energetic forces that originated both within and beyond the being of an individual, to encourage an action related to the behaviour and to determine its shape, direction, intensity and duration. Another scholar, Luthan (1998) defines motivation as "a process that starts with a physiological deficiency or a need that activates a behaviour that aims to encourage an action". Therefore the key to understand the process of motivation is to understand the relationship among needs, incentives and stimuli.

Motivation also is an issue that is influenced by many factors. No factor can guarantee motivation when other factors lack. The impact of motivational factors is important for the commitment of the employees.

When employees are motivated they will be satisfied with their organisation and will understand that their organisation is paying them sufficient attention and considers them as important factors. The satisfied employees will commit themselves in positive behaviour. One of these bahaviours might be organisational commitment. It has long been established that organisational commitment is an important factor that contributes to increase the level of individual productivity leading to an increased level of organisational productivity, therefore examination of these variables that contribute to improve th level of organisational commitment has always been of special interest for researchers and scholars in the field of human resources management, which was another strong reason to carry out this research.

\section{Organisational Motivation and Commitment at Work}

The concept of organisational commitment is a relatively new concept in the field of Organisational Menagement and Psychology which is separately studied.

The comparison between the definitions of motivation and commitment reveals a clear similarity: Both have been described as enegetic forces and with consequences for the behaviour. Pinder (1998) described motivation as a group of energetic forces, whereas Meyer and Herscovitch (2001) described commitment as a force related to a certain action of an individual. This means that motivation is a broader concept than commitment and that commitment is a group of energetic forces that contributes to motivate behavior. However, the obligatory nature of commitment makes it rather unique among many forces. Even when commitment is involved, motivation can diminish over time, with the growth and reduction of commitment. Nevertheless, commitment can serve as a specifically powerful motivation source, even against opposing forces (Brickman, 1987; Scholl, 1991). An engaged workforce can increase productivity and performance, thus contributing to the growth and strengthening of the institution. Most managers should have a clear need for improvement and employees' commitment to develop tangible ways to address and study this phenomenon. According to Meyer and Herscovitch et.al (2001) commitment is a force in which an individual is linked to a course of action that is important for a certain target. So, studying this phenomenon, alongside with motivation and performance, is very important, due to the fact that it is an important indicator of the will, effectiveness and productivity at work of both employees and the organisation as a whole.

\section{Methodology}

\subsection{Methodology}

This scientific study has as a main research object the description and analysis of its two key variables, such as 
organisational motivation and commitment of teachers in the educational institution in the region of Tirana and Elbasan. The focus is the impact and importance that the motivating factors have in the organizational commitment of teachers. A survey consisting of two questionnaires was used to measure these variables. One was the Motivation at Work questionnaire, by Robert P. Brady (2011), which was developed and revised by this author, but was used in many studies or the employees' Motivation at Work. This instrument was taken from an on-line magazine which clearly explained the scoring of the answers received. The second instrument that is used is that of Organisational Commitment. In this study were included teachers of the pre-university system, from the three levels of primary education, lower secondary and upper secondary education. The schools that had the largest number of teachers were included in the study in order to have a much clearer and precise picture of the objective and research aspect of the study. The sample was selected based on the methodology of quantitative research. This sample from the selection strategy is a random sample with a set probability of 1 in 3 teachers in the selected schools.

The number of teachers with which the analysis began was No $=1000$, out of whom $74.9 \%$ of are females (no. $=$ 749 ) and $25.1 \%$ of them consisted of men (no. $=251$ ) with a statistically significant difference between them. The average age of participants ranged from 23 years old the minimum age to 65 years old the maximum age.

The number of teachers at the start of the analysis was No. $=1000,74.9 \%$ of whom are females (no. $=749$ ) and $25.1 \%$ of whom are males (no. $=251$ ) with a statistically significant difference between them. The participants' average age ranged from 23 years old, minimum age and 65 years old, maximum age.

Participation in the study was completely voluntary and confidential. Participants were informed on these issues before being included in the study. Once the participants declared themselves ready to engage in the study they underwent questionnaires. The graduate distributed the questionnaires to each teacher and he/she explained them the purpose of this study and also informed them on the issues of confidentiality and anonymity.

The instrument: In this study was used "The Questionnaire on Work Motivation" from Robert P. Bradly(2011) ${ }^{1}$ taken from a scientific magazine. This instrument was developed and revised by this author and was used in many studies that explored the employees' work motivation. This instrument was taken from an open source website that allowed the use of this instrument. Along with the instrument it also provides the key to scoring the answers received. This questionnaire consists of 31 statements and is divided into 8 dimensions which give the motivating factors. Based on the division of these dimensions 2 subscales are created: external motivation and internal motivation. Scoring was done in such a way that as many points a person has, the more internally or externally motivated he is.

The Organisational Commitment Questionnaire, used by (Meyer \& Allen, 1993). The questionnaire consists of 18 statements. Responses range from 1- Strongly Disagree to 5- Strongly dont't agree. The answers to statements are coded in such a way that higher results reflect a high commitment of employees in the organisation where they work and lower results reflect a low commitment of the employees in the organisation where they work. Some of the statements are eliminated in order to avoid same answers.

\subsection{Measurement}

In order to give answers to the research questions raised in this study following we give the analysis on these questions: këto pyetje:

Për ti dhënë përgjigje pyetjve kërkimore të ngritura në studim, më poshtë jepen të pasqyruara anlizat e kryera për

Research question: Does work organisational commitment depend on motivating factors, such as Payment and benefits, Work conditions, Relations with colleagues, Relations with managers, Task Orientation, Cooperation with colleagues, Orientation towards Goal and Orientation towards success? Which ones affect most?

In order to give an answer to this question data analysis was based on the creation of the equation of linear multiple regression. The analysis showed that three out of eight factors mostly impact the teachers' work commitment. These factors are Task Orientation, Cooperation with colleagues and Success orientation where the Success Orientation factor gives the greatest impact, having the highest coefficient, $\beta=0.157$, followed by the cooperation with colleagues and task orientation. We should point out that all coefficients of this regression equation are positive, which means that with the growth of each factor with one unit the dependant variable also increases by coeffiecients $\beta$. So, the above three factors have a greater impact compared to the other motivation factors, also explaining the $14.3 \%$ of the values of change variancy of the work organisational commitment variables. So in this case it should be noted the fact that teachers in these districts are more oriented towards success, considering it as important in their teaching performance

${ }^{1}$ Work Motivation Scale, Robert Bradly (2011), Catalog IJST 2010, pg.30 
of the teaching process.

The regression equation is:

(Work organisational commitment) $=1.721+0.071$ (Task Orientation) +0.086 (Cooperation with colleagues) + 0.157 (Success orientation)

Table 37 Multiple regression analysis between independant variables and the dependent variable work irganisational commitment

\begin{tabular}{|l|c|c|c|c|}
\hline Model & $\mathrm{R}^{2}$ & $\mathrm{R}^{2}$ Adjusted & $\mathrm{t}$ & $\mathrm{Sig}$. \\
\hline Constant & .150 & .143 & & .000 \\
\hline Payment and benefits & & & 1.522 & .128 \\
\hline Work conditions & & & 1.685 & .092 \\
\hline Relations with colleagues & & & 1.157 & .247 \\
\hline Relations with managers & & & .162 & .871 \\
\hline Task orientation & & & 1.919 & .050 \\
\hline Cooperation with colleagues & & & 3.931 & .000 \\
\hline Goal orientation & & & .225 & .822 \\
\hline Success orientation & & & 4.625 & .000 \\
\hline
\end{tabular}

As pointed out above, our sample contains information from teachers who work not only in urban areas, but also in rural areas and each of them has a different experience teaching in different cycles also. Therefore another question raised in this research is based on who are mostly committed at work, the rural areas teachers or urban areas teachers.

Are there visible differences among teachers' work commitment depending on the fact that the teacher works in urban or rural area?

Test $t$ on independant elections showed that the value of $S i g=0.130>0.05$ demonstrates that the variances of these groups are equal, so groups are homogeneous. This is evident from the data on their averages associated with organizational commitment at work where $\mathrm{M}_{\text {urban }}=3.61$ and $\mathrm{M}_{\text {rural }}=3.64$ therefore for $\mathrm{a}=5 \%$ and $\mathrm{t}(-0.715)$ we can say that the value of Sig (2-tailed) is $0.475>0.05$ which shows that this difference of averages s not statistically important. So, we definitely say that teachers' work organisational commitment makes no difference whether the teacher works in an urban or rural area. Thus teachers consider their commitment in the teching process important, regardless of the area where they work. This conclusion is also confirmed by the Chi Square Test, where the value of the Pearson coefficient is $0.331>0.05$ indicating that the teachers' work organisational commitment and the area where they work (urban/rural) are independant variables.

\section{Discussion on te Results}

The aim of this study was to study the phenomena of the motivating factors and organisational commitment of the educational institution's employees in the districts of Tirana nad Elbasan and also to see who are most commited at work, teachers in urban areas or those in rural areas. Nowadays, it is known that the motivating factors affect the general work culture in an organization / institution and the findings also show that organizational commitment affects the organizational effectiveness through motivation. It is already known that motivated employees and motivating factors affect the overall success of an organization / institution. However, different employees have different types of motivational factors. The study results showed that teachers in their work performance were more orientated towards being successful in their individual work and in their work with students. What is also interesting in this study is the fact that teachers both in urban and rural areas show the same work commitment, displaying no differences, which shows a similar commitment and desire for their work and the perfection of their performance at work, despite the conditions in which they are.

Considering this result, teachers should be constantly motivated as motivational factors have a great importance for their commitment at work and it is quite interesting the fact that they are more oriented towards success, as a key work motivating factor, so the teachers' will to work as much as possible in order to be more successful in their work. 


\section{Conclusion}

The data collected were conducted further analysis in terms of motivational factors of employees in this institution. It investigated how motivated they were employees concerning, salary and benefits, working conditions, relationship with colleagues, relations with director, supervising others, orientation towards the tasks, goals and orientations toward success. Conclusion resulting from referring percentages in which teachers are motivated are expressed that have high motivated that it can be concluded that teachers in this institution are motivated more by external factors compared to inxtrinsic motivation. The analysis conducted corelacionare between organizacional commitment and motivation dimensions of organizational commitment showed that there is a statistically significant relationship with the supervision of others, towards the goal orientation, orientation towards success and working conditions. Correlations between engagement and motivation are positive that show the importanc of motivation in the work of the teaches. The table shows that there are significant relationships between satistikisht relationships with colleagues and relations with the boss, salary supervision and working conditions, success orientation and orientation tasks and marrdhënive boss. So we can say that all motivational factors have importance in the work that reflected directly in the high education of the pupils.

\section{Recomandations}

Provide a suitable environment in schools to positively enforce the teachers' commitment.

Carry out functional conversations with teachers on the morivating factors that can motivate them in their work performance.

Leaders should recognize the motivational processes that have more impact on teachers in order to enhance and motivate as much as possible their commitment at work.

Encourage and support teachers in their new ideas, especially to innovation they want to bring about in their work. This would further commit and motivate them to do their work.

\section{References}

Analoui, F (2000), What motivates senior managers? The case of Romania Journal of Managerial Psychology, Vol.15, No.4 pp.324-340, University of Bradford, Bradford Uk

Brickman, P. (1987). Commitment. In B. Wortman \& R. Sorrentino (Eds.),Commitment, conflict, and caring (pp. 1-18). Engleëood Cliffs, NJ: Prentice Hall.

Mitchell, T. R., \& Daniels, D. (2003). Motivation. Handbook of Psychology, Vol. 12. Industrial Organizational Psychology, ed. Ë.C. Borman, D.R. Ilgen, R.J. Klimoski, pp. 225-54. Neë York:Wiley.

Meyer, J.P. \& Herscovitch, L. (2001). Commitment in the workplace: Toward a general model. Human Resource Management Review, $11,299-326$.

Meyer dhe Herscovitch et.al (2001) "Employee commitment and motivation: A conceptual analysis and integrative model "Journal of Applied Psychology 2004, Vol.89, No.6 pg.993

Mowëday, R. T., Porter, L. W., \& Steers, R. M. (1982). Organizational linkages: The psychology of commitment, absenteeism, and turnover.San Diego, CA: Academic Press

Pinder, C. C. (1998). Motivation in work organizations. Upper Saddle River, NJ: Prentice Hall.

Tung, L. R. 1981. 'Patterns of Motivation in Chinese Industrial Enterprises', The Academy of Management Revieë, vol. 6, no. 3, pp. 481489. 